\title{
Historical changes in extreme precipitation events in the tropical Pacific region
}

\author{
J. Scott Greene ${ }^{1, *}$, Bryan Paris ${ }^{2}$, Mark Morrissey ${ }^{3}$ \\ ${ }^{1}$ Department of Geography, University of Oklahoma, Norman, Oklahoma 73019, USA \\ ${ }^{2}$ Department of Geography, Arizona State University, Tempe 85287, Arizona, USA \\ ${ }^{3}$ School of Meteorology, University of Oklahoma, Norman, Oklahoma 73019, USA
}

\begin{abstract}
Historical changes in tropical Pacific rainfall are analyzed using data from the newly enhanced Comprehensive Pacific Rainfall Database (PACRAIN), a daily rain-gauge database for the Pacific that contains almost 800 sites, some with records dating back to the 1800 s. After a complete analysis of the database, 24 stations were selected to examine rainfall changes from 1971 to 2000 using daily data. In addition, a series of extreme event indicators, such as the percent of annual precipitation that falls on days exceeding the 99th percentile, were selected and analyzed in accordance with the World Meteorological Organization (WMO) guidelines for analysis of extreme events. Historical precipitation records in the central and southwestern tropical Pacific showed a trend towards decreasing precipitation during the period 1971 to 2000. This is consistent with previous research on changes from 1971 to 1990, as well as previous results that use data from a different set of stations. There was an increase in the characteristics of extreme precipitation events in most locations, even in those with a decrease in overall precipitation. This could have significant impacts in a hydrological sense, and illustrates the need to use extreme event variables when analyzing climatic patterns. Longer-term patterns were revealed through an analysis of monthly data from 14 stations over the period 1951 to 2004. Results suggest that the role of the Interdecadal Pacific Oscillation (IPO), especially the positive phase, could be important in explaining a significant amount of the observed changes.
\end{abstract}

KEY WORDS: Tropical Pacific precipitation · Trend analysis · Extreme rainfall events

\section{INTRODUCTION}

An important potential consequence of a changing climate is a change in the severity and occurrence of precipitation events. Changes in extreme precipitation events are of particular importance in low-lying areas vulnerable to precipitation-driven disasters such as flooding. Included in this high risk group are the island groups of the tropical Pacific, which are typically small in area and separated by large expanses of ocean. Changes in weather patterns (e.g. increase/decrease in tropical cyclones; changes in patterns of major convergence zones) would, at the very least, affect agriculture and ocean fishery industries. The natural climate variability associated with the El Niño Southern Oscillation (ENSO) phenomenon can also have a sig- nificant impact on the social and economic activities of the islands.

In addition to the long-term trends identified and described by the Intergovernmental Panel on Climate Change (Houghton et al. 2001) and others, there is a need to examine changes in the mean and the variability in extreme events. For example, Meehl et al. (2000) illustrated the impact that climatic extremes can have on the natural environment and human society. Extreme precipitation events have increased in the United States, China, Australia, Canada, Norway, Mexico, Poland and Russia (Easterling et al. 1997, Groisman 2000). Previous studies on selected stations in the southern tropical Pacific (Manton et al. 2001, Griffiths et al. 2003) also revealed changes in the character and severity of precipitation across the Pacific 
region. For example, both the South Pacific Convergence Zone (SPCZ) and the Inter-Tropical Convergence Zone (ITCZ) have been known to vary in location on interannual and decadal time scales (Vincent 1994, Folland et al. 2002). These changes in position have been attributed to the polarity of the Interdecadal Pacific Oscillation (IPO) and ENSO.

Understanding changes in climate variability and climate extremes is made difficult by interactions between the changes in mean and variability. As mentioned above, extremes in precipitation have important impacts on vital aspects of environment and society, including crop yields, power consumption and production, and human health. This study used recent standard methodology (described below) to examine the overall changes in extreme precipitation events across a region in the southwestern tropical Pacific, and expands upon previous results by including stations from the Comprehensive Pacific Rainfall Database (PACRAIN; Morrissey et al. 1995), which were not analyzed in previous studies. Inclusion of additional locations allows for an expanded analysis of the spatial patterns of the changes in extreme event precipitation across the study region in the central and southwestern tropical Pacific.

\section{DATA AND METHODS}

One of the most useful environmental measurements for the monitoring of climate is rainfall, because it is a primary driver of diabatic heating in the tropical atmosphere as well as a critical parameter in modeling the hydrologic cycle. Unfortunately, rainfall observations (as well as measurements of other environmental parameters) are extremely sparse within the tropical oceans. However, this study used a data set consisting of a wide range of precipitation data throughout the tropical Pacific, especially focused on the central and southwestern Pacific (see Fig. 1a). For this study, this data set was used to examine not only the traditional approach to the examination of trends (e.g. linear trends in mean annual precipitation), but also to analyze the changes in extreme characteristics of precipitation.

\subsection{Data used}

This analysis used data from the PACRAIN, a database of rainfall observations from throughout the tropical Pacific region (Morrissey et al. 1995) that merges rainfall records from various weather agencies and other sources into a unified format and makes them available via the world wide web (http://pacrain.evac.ou.edu). Fig. 1a shows the distribution of all stations that have recorded data and are contained in the PACRAIN. The PACRAIN project is also part of the Pacific Island Global Climate Observing System (PI-GCOS) initiative to expand and enhance observation networks in the tropical Pacific (see http://pi-gcos.org).

Analysis and quality control of PACRAIN data are essential and are considered an operational task by the PACRAIN administrators, because data collection in the Pacific is a variable and sometimes inconsistent process. The PACRAIN database consists of daily and monthly raingauge data from stations throughout the tropical Pacific, with some records going back to the 1800s. Many of these data were collected through arrangements with local Pacific meteorological services, as well as the New Zealand National Institute of Water and Atmospheric Research (NIWA), Meteo-France, and the US National Climatic Data Center. The database currently contains more than 2 million records from over 700 sites. This includes daily data from 1971 to the present. There are also more than 40000 monthly observations from 133 sites, for the period 1874 to 1970 .

A unique and key component of the PACRAIN database is the Schools of the Pacific Rainfall Climate Experiment (SPaRCE; Postawko et al. 1994). Over 200 schools, technical centers and other local organizations across the Pacific collect data as part of the global climate research effort. Each organization is equipped with a direct read raingauge, a GPS, a camera, and detailed instructions on setup and maintenance of a professional weather observation site. Each local participant group takes daily rainfall measurements, which are quality controlled and then provided to the research community through inclusion in the PACRAIN database. The SPaRCE program also supplies participants with educational material (e.g. books, video tapes) and provides workshops in an effort to increase awareness of the necessity of enhancing the quality and quantity of Pacific environmental data.

\subsection{Metadata}

As described by Nicholls (1995), measurement errors are more likely to influence estimation of changes in extreme events than changes in means. Thus, changes in station location and instrument type etc. affect extreme measurements more so than means. Metadata become increasingly important when looking at extreme events, because extreme event indicators are sensitive to outliers and inhomogeneities. One advantage of using the PACRAIN is the high level of metadata information available, as well as the rigorous quality control that the data have undergone (Morrissey et al. 1995, Greene \& Morrissey 2000). 

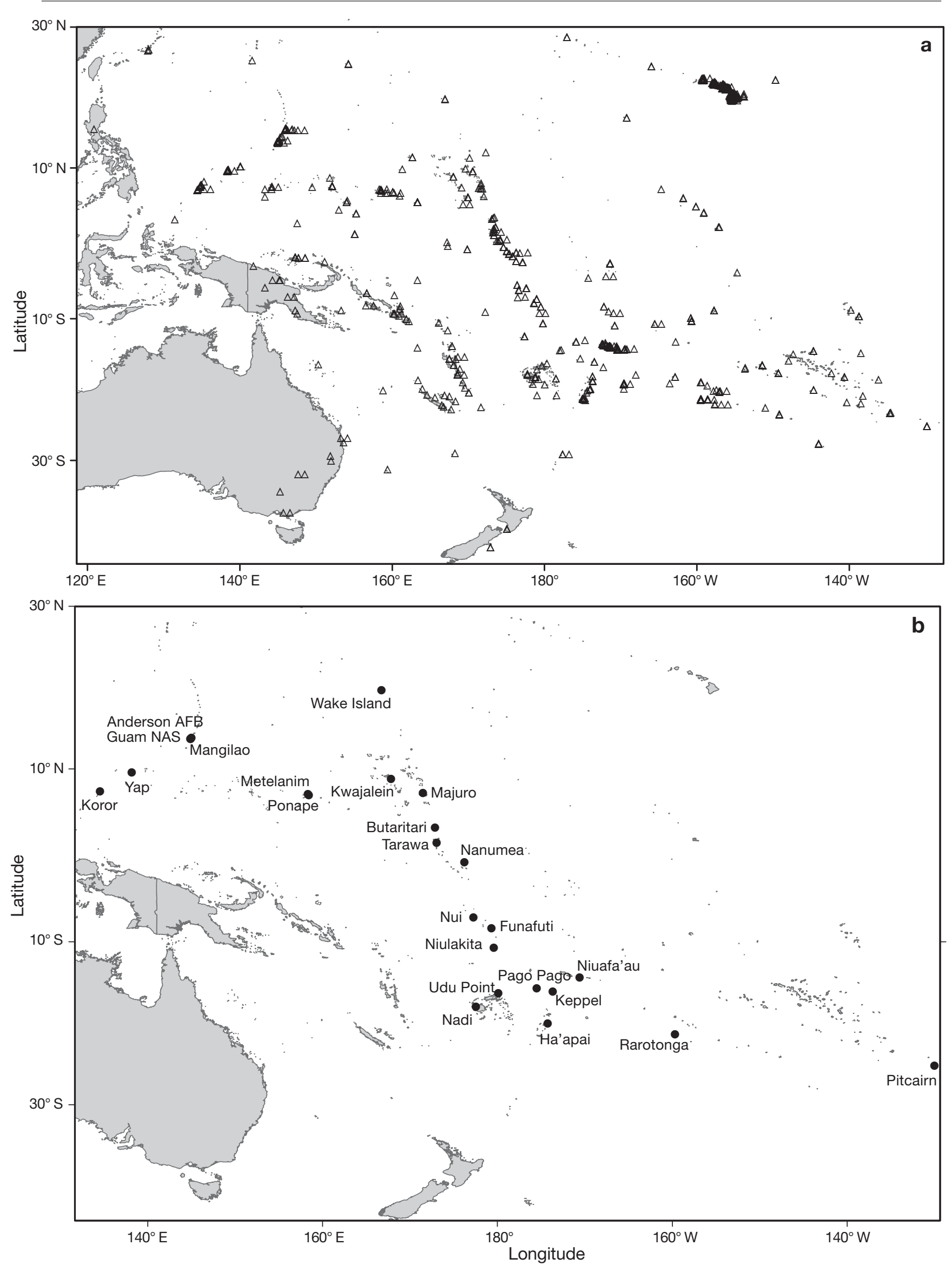

Fig. 1. (a) Location of stations in the Comprehensive Pacific Rainfall Database (PACRAIN). (b) Location of stations used in the analysis 
Table 1. Metadata for stations used in analysis. Negative latitudinal and longitudinal coordinates represent S and E, respectively

\begin{tabular}{|c|c|c|c|c|c|c|c|}
\hline ID & Station & Country & $\begin{array}{l}\text { Latitude } \\
\text { (ddmm) }\end{array}$ & $\begin{array}{l}\text { Longitude } \\
\text { (dddmm) }\end{array}$ & $\begin{array}{l}\text { Elevation } \\
\quad(\mathrm{m})\end{array}$ & $\begin{array}{l}\text { Start of Record } \\
\text { (yyyymmdd) }\end{array}$ & $\begin{array}{l}\text { End of Record } \\
\text { (yyyymmdd) }\end{array}$ \\
\hline 1 & Anderson AFB & Guam & 1335 & 14455 & 190 & 19521231 & 20021130 \\
\hline 2 & Butaritari & Kiribati & 304 & 17247 & 2 & 19310701 & 20021126 \\
\hline 3 & Funafuti & Tuvalu & -831 & 17912 & 1 & 19270701 & 20030731 \\
\hline 4 & Guam NAS & Guam & 1328 & 14447 & 77 & 19450901 & 20051031 \\
\hline 5 & Ha'apai & Tonga & -1948 & -17421 & 2 & 19311101 & 20031031 \\
\hline 6 & Keppel & Tonga & -1557 & -17346 & 2 & 19311101 & 20040504 \\
\hline 7 & Koror & Palau & 719 & 13428 & 29 & 19510701 & 20051031 \\
\hline 8 & Kwajalein & Marshall Islands & 843 & 16744 & 2 & 19450101 & 20051031 \\
\hline 9 & Majuro & Marshall Islands & 705 & 17122 & 3 & 19540430 & 20051031 \\
\hline 10 & Mangilao & Guam & 1327 & 14449 & 18 & 19700630 & 20051030 \\
\hline 11 & Metelanim & Pohnpei & 651 & 15819 & 9 & 19670228 & 20050730 \\
\hline 12 & Nadi & Fiji & -1609 & 18000 & 19 & 19530101 & 20040412 \\
\hline 13 & Nanumea & Tuvalu & -54 & 17607 & 2 & 19470101 & 20040601 \\
\hline 14 & Niuafa'au & Tonga & -1534 & -17537 & 60 & 19710101 & 20031022 \\
\hline 15 & Niulakita & Tuvalu & -1047 & 17928 & 3 & 19710101 & 20030430 \\
\hline 16 & Nui & Tuvalu & -715 & 17709 & 2 & 19470101 & 20040930 \\
\hline 17 & Pago Pago & American Samoa & -1419 & -17042 & 3 & 19660401 & 20051031 \\
\hline 18 & Pitcairn & Pitcairn & -2504 & -13006 & 8 & 19400301 & 20051031 \\
\hline 19 & Ponape & Pohnpei & 657 & 15813 & 37 & 19280101 & 20051031 \\
\hline 20 & Rarotonga & Cook Islands & -2111 & -15948 & 7 & 18990101 & 20050727 \\
\hline 21 & Tarawa & Kiribati & 121 & 17256 & 2 & 19260701 & 20030911 \\
\hline 22 & Udu Point & Fiji & -1746 & 17727 & 49 & 19460701 & 20030101 \\
\hline 23 & Wake Island & Wake Island & 1917 & 16638 & 3 & 19350701 & 20040531 \\
\hline 24 & Yap & Yap & 928 & 13805 & 13 & 19510701 & 20051031 \\
\hline
\end{tabular}

For this study, a strict criteria of at least $99 \%$ data completeness for the time period under examination (the latest climate normal period of 1971 to 2000) was necessary for the station to be included in the analysis. Checks for station and instrument moves, as well as inconsistencies in the data, were also undertaken. Those stations with a complete record but known problems or inhomogeneities were removed from the analysis. For example, some stations that had a complete data record had a suspiciously high frequency of zero precipitation during the weekends, and an extremely high occurrence of precipitation on Mondays. Statistical tests regarding the percent occurrence and mean precipitation for those stations showed that the most likely explanation was a lack of observation during the weekend rather than actual zero precipitation. Since the weekend values were not recorded, the Monday values were most likely accumulations over a $3 \mathrm{~d}$ period rather than observations from $1 \mathrm{~d}$. Those stations that had this day-of-week bias or other similar inhomogeneities were removed for the purposes of this study, because accurate and complete daily records are needed to compute the extreme event variables. Finally, concern over the potential effect of orography and land-ocean temperature gradients on the representativeness of island raingage measurements of open ocean conditions limited the stations selected to those with a low elevation of 200 m or less. Ultimately, over half of the stations finally included in this study had elevations of $10 \mathrm{~m}$ or less. In addition, some stations showed evidence of highly unrealistic outliers. These outliers would have dramatically skewed the interpretation of the point-specific and regional patterns in the changes, and were thus eliminated from further analysis. While a reduced criteria for inclusion would have allowed for more stations in this study, the addition of stations with potentionally erroneous data could result in misleading results and interpretation. This is particularly true for the extreme event analysis, where the inclusion of the 'Monday anomaly' or nonatoll stations in the analyses could potentially give erroneous results. Table 1 gives the names, locations, elevation, and period of record for the 24 stations that were ultimately selected for this study, and their locations are shown in Fig. $1 \mathrm{~b}$.

For the first part of the analysis, daily data was required to compute the extreme event indicators. Most of the daily records began in 1971, which corresponds to the current climate normal period; thus, January 1, 1971 was the day selected as the start date for the daily trend analysis. Similarly, December 31, 2000 was selected as a standard end date and to facilitate the comparison of results with climate normal values. The second part of the analysis used monthly data to investigate an explanation of the cause behind the changes. The period of analysis here is 1951 to 2004, which corresponds with distinct phases of the IPO (Folland et al. 2002). Stations that met the strict requirements 
described above (e.g. 99\% complete, as well as low elevation, no known biases etc.), and also possessed a sufficiently complete data record for that period, were used in the longer term monthly analysis.

\subsection{Analytical methods}

As mentioned above, a key question regarding a changing climate is 'are climate extremes becoming more frequent?' Examples from previous studies described above illustrate that analyses of extreme rainfall studies are becoming more common as scientists try to answer that question. A recurring problem with older analyses has been inconsistent methods of measuring or defining extreme events. Recent efforts, however, have attempted to standardize the variables used in extreme event analysis (e.g. Peterson et al. 2002). For example, Nicholls \& Murray (1999) recommend a set of indicators that include the following: variations in the magnitude of particular percentile values, and percentage of annual precipitation falling on days with rainfall above a specified percentile (e.g. 99th).

Thus, a set of climate extremes was selected for this study from the internationally agreed World Meteorological Organization (WMO) list of climate indicators. Table 2 shows the list of indicators analyzed in this study. The first, annual precipitation, is not a measure of extreme precipitation per se, but was included here for comparison with other studies, and also to provide a baseline for the examination of the other variables. The number of days with measurable (e.g. above trace) precipitation for each year was included to examine the character of the frequency of all precipitation events. The other indicators: extreme frequency, intensity, and proportion at the 99th percentile, were included to examine the relative change in the amount and character of the heaviest rainfall events for each location. For example, extreme proportion was determined as follows: the amount of daily rainfall associated with the 99th percentile value for each year at each location was computed, and then the proportion of total annual rainfall for each year that fell during those days that exceeded the computed 99th percentile threshold was calculated. Thus, each year for each station has a value of the percentage of rainfall that fell during values that exceeded the 99th percentile threshold. The linear changes over the $30 \mathrm{yr}$ period was then determined and the spatial patterns are presented in the figures that follow. Linear trends were determined because for most stations this is the approach that produced the most accurate curve fit. Although in a few instances the yearly time series fit a curvilinear pattern, the goal was to select a consistent method to best compare the spatial pattern of the changes. Statistical significance tests were performed on the trend lines, and the figures show those values that are statistically different from zero $(\alpha=0.05)$.

Although the changes are computed on a year-toyear basis, complete daily data are needed to compute the 99th percentile value, and the associated intensity of the days above that threshold for a given year. For example, over the course of a year that contains $365 \mathrm{~d}$, the 99 th percentile value would refer to $3 \mathrm{~d}$ of precipitation totals. Following Suppiah \& Hennessy (1998), a variety of other indicators (e.g. 5 d rainfall totals, changes in conditional and unconditional precipitation at a range of percentiles etc.) were also examined. Thus, in addition to the use of the 99th percentile value, as illustrated for the extreme variables in Table 2, the extreme events associated with the 50th, 75th, 90th, and 95th percentiles were also computed. However, these indicators were found to be highly correlated over time with the indicators listed in Table 2, thereby adding little new information. Hence, those results are not included in this study. The analysis below focuses on the indicators described and outlined above.

\section{EXTREME RAINFALL CHANGES}

\subsection{Results: regional patterns of changes}

The first analysis was a calculation of the overall change in annual precipitation for the study region and period (1971-2000) (Fig. 2). For Figs. 2 \& 4-11 in this study, those values not statistically significant from zero (at $95 \%$ confidence intervals [CI]) are shown with a filled-in circle, and those that are different from zero are shown with either increasing or decreasing triangles to indicate the direction of the change. The most significant pattern in Fig. 2 is a decrease in total annual rain over the time period analyzed. Seven stations showed statistically significant decreases (19 stations showed decreasing rainfall overall), and none showed significant increases. The most pronounced pattern is located in the south-central and western regions of the study area. For example, Udu Point and Niulakita both have pronounced decreases, with the decrease over $30 \mathrm{yr}$ resulting in current annual precipitation of $>600 \mathrm{~mm} \mathrm{yr}^{-1}$ less than at the beginning of the study period. This pattern fits previous research (Salinger et al. 2001), suggesting that the decrease in the southwestern portion of the study region is likely associated with a displacement of the SPCZ during the analysis period. Specifically, the area most likely to show a statistically significant decrease contains the stations located just south of the mean location of the SPCZ. However, the decrease shown would indicate increasing distance from the SPCZ over time, which would 


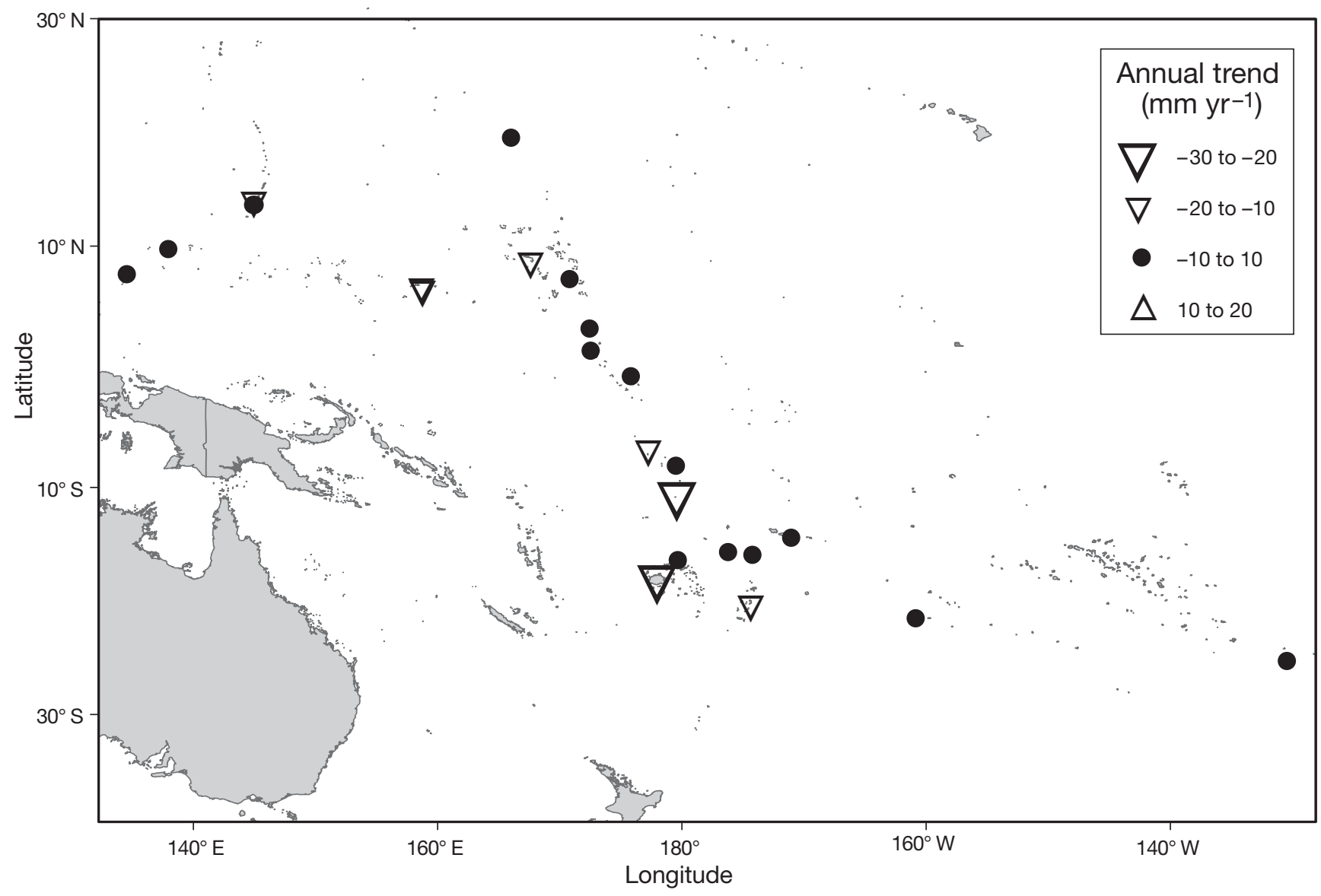

Fig. 2. Change in total annual precipitation, 1971-2000

support the displacement mentioned above. The pattern in the far western Equatorial Pacific shows the station changes remaining relatively flat (e.g. Koror), or increasing by a small and statistically insignificant amount (e.g. Yap, Guam). This pattern of no or slight changes in the annual precipitation in the northwest portion of the study region shows some similarity to the

Table 2. Extreme value indicators used in this study

\begin{tabular}{|c|c|}
\hline Indicator & Description \\
\hline $\begin{array}{l}\text { Annual precipitation } \\
(\mathrm{mm})\end{array}$ & $\begin{array}{l}\text { Total average annual precipitation } \\
\text { tion during the study period, } \\
1971-2000\end{array}$ \\
\hline $\begin{array}{l}\text { Extreme frequency } \\
(\%)\end{array}$ & $\begin{array}{l}\text { Frequency of daily rainfall exceed- } \\
\text { ing the mean 99th percentile }\end{array}$ \\
\hline $\begin{array}{l}\text { Precipitation days } \\
\text { (d) }\end{array}$ & $\begin{array}{l}\text { Frequency of days with measurable } \\
\text { precipitation }\end{array}$ \\
\hline $\begin{array}{l}\text { Extreme intensity } \\
(\mathrm{mm})\end{array}$ & $\begin{array}{l}\text { Average intensity of events greater } \\
\text { than or equal to the 99th percentile } \\
\text { each year }\end{array}$ \\
\hline $\begin{array}{l}\text { Extreme proportion } \\
(\%)\end{array}$ & $\begin{array}{l}\text { Percentage of annual total rainfall } \\
\text { from events greater than or equal } \\
\text { to the designated percentile }\end{array}$ \\
\hline
\end{tabular}

previous findings of Morrissey \& Graham (1996), who studied rainfall over a shorter time frame (1971 to 1990).

The main purpose of this study was to expand the description of changing precipitation patterns in the tropical Pacific by investigating not only the mean rainfall fields, but also the changes in the extreme event indices described above. Fig. 3 uses 1 location, Udu Point, Fiji, to illustrate the importance of expanding the research beyond the simple linear trend of annual precipitation (NB: one year, 1989, is missing from these figures; however, a Monte Carlo analysis of the possible range of values that the missing value might take was performed, and there was no significant alteration to the overall trend pattern). Fig. 3a shows the trend in the annual rainfall, as well as the $95 \%$ CI for the trend line. As mentioned previously, the result over the study period is a drop from over $2500 \mathrm{~mm} \mathrm{yr}^{-1}$ to less than $2000 \mathrm{~mm} \mathrm{yr}^{-1}$. Fig. 3b provides some explanation for this pattern. The number of days with measurable precipitation decreased by over $20 \mathrm{~d} \mathrm{yr}^{-1}$ from about 140 to less than $120 \mathrm{~d}$. Thus, both the number of days of rain and the annual precipitation showed noticeable and significant decreases over the 

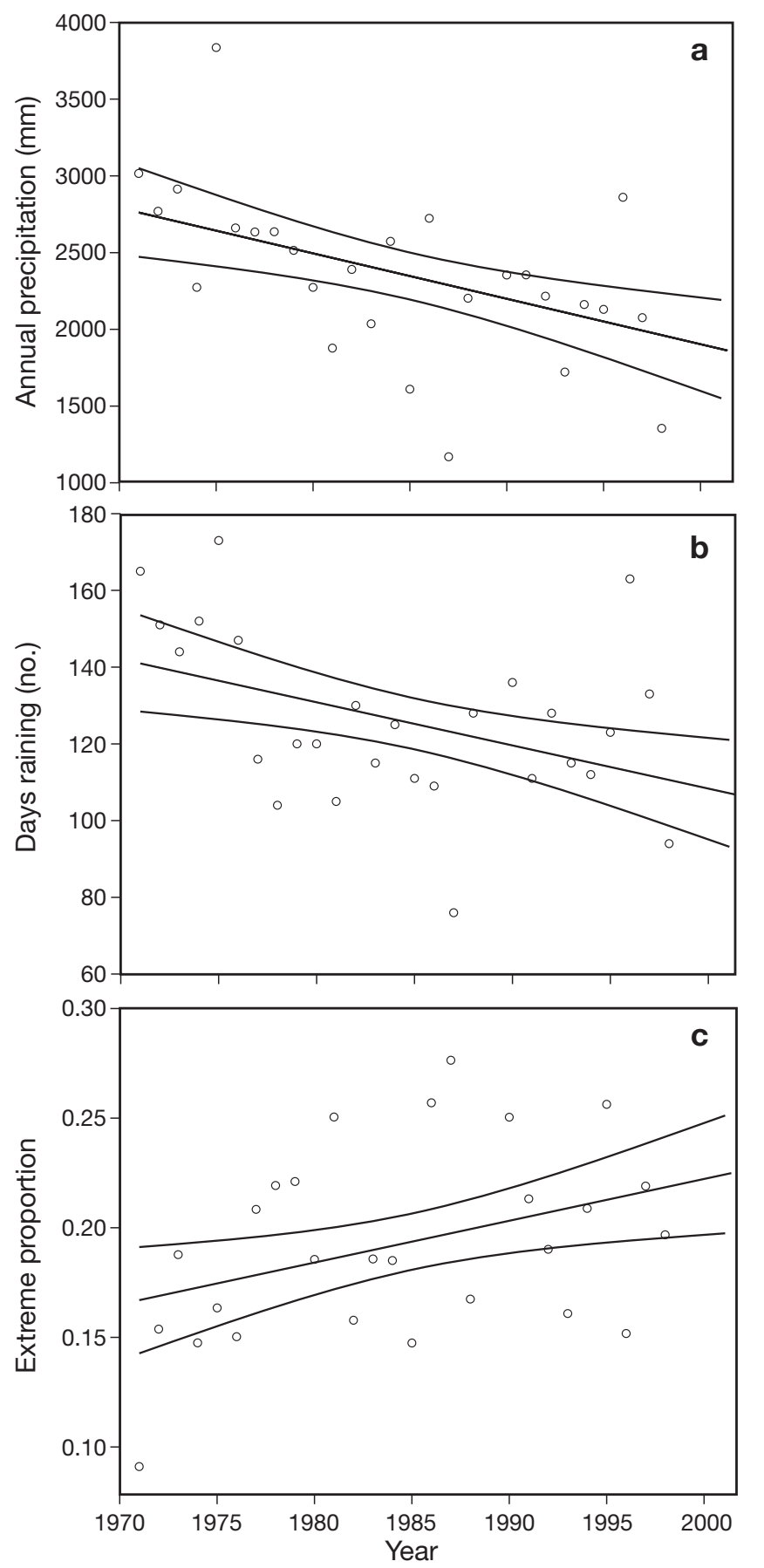

Fig. 3. (a) Trend (and 95\% CI) in annual precipitation at Udu Point, Fiji. (b) Trend (and 95\% CI) in no. of days of rain at Udu Point. (c) Trend (and 95\% CI) in extreme proportion of precipitation at Udu Point

study period. However, the proportion of rainfall that fell during extreme days (defined as those days with more than the 99th percentile value for precipitation, $111 \mathrm{~mm} \mathrm{~d}^{-1}$ in the case of Udu Point) increased by approximately one-third from $16 \%$ to over $20 \%$.
Clearly, although total annual precipitation has been decreasing, the amount of extreme events has been increasing. Since extreme events are significant from a water-driven hazard standpoint (e.g. flood potential), Fig. 3c may be of more importance in describing the changing climate at this location to e.g. an emergency planner, and illustrates the importance of looking at values other than annual precipitation.

The next 3 figures (Figs. 4, 5, \& 6) illustrate the patterns of the changes in extreme proportion, intensity, and frequency of precipitation for the study region and period. Each of these is based on the analysis and comparison of the 99th percentile values, as described above. The most striking results are the changes in extreme proportion, as shown in Fig. 4 when compared with the results shown in previous figures (e.g. Fig. 2). As in the case of Udu Point illustrated above, there are several additional stations that show a pronounced increase in the percentage of total precipitation that falls during the heaviest $1 \%$ of days. Overall, 8 stations show a statistically significant increase in this indicator. Recall that no stations showed a statistically significant increase in total precipitation. There is also a clear geographic distribution of this indicator, with stations in the south and southeastern portion of the study region showing the greatest values, and the highest percentage of stations with statistically significant values. This result shows that, although the total annual precipitation is decreasing, the amount of overall rainfall during the heaviest rainfall days is increasing. Of further note is that this is the same general geographic region that experienced the largest drop in total annual annual precipitation. It is suggested that the overall drop is associated with a general shift in the SPCZ. The increase in extreme events may indicate that there is an increasing number of individual days (rather than overall patterns) in which strong convergence is associated with heavy precipitation. This might argue for increased amounts of localized rainfall rather than for a broad-based convergence zone. An analysis of tropical cyclone paths and intensities performed as part of the PACRAIN data quality control revealed that increased tropical cyclone activity is not a possible explanation for the pattern shown.

Although the amount of total precipitation explained by the highest rainfall days is increasing in many locations, the average amount (intensity) falling on those days is not (Fig. 5). The average amount of rainfall on those highest $1 \%$ of days shows a slight decline or relatively no change. There are a few stations that show a statistically significant trend, but there is no clear or consistent spatial pattern. Similarly, the change in the number of days per year that exceed the $1 \%$ threshold showed a slight decrease over time (Fig. 6), with the spatial pattern similar to the overall pattern of annual 


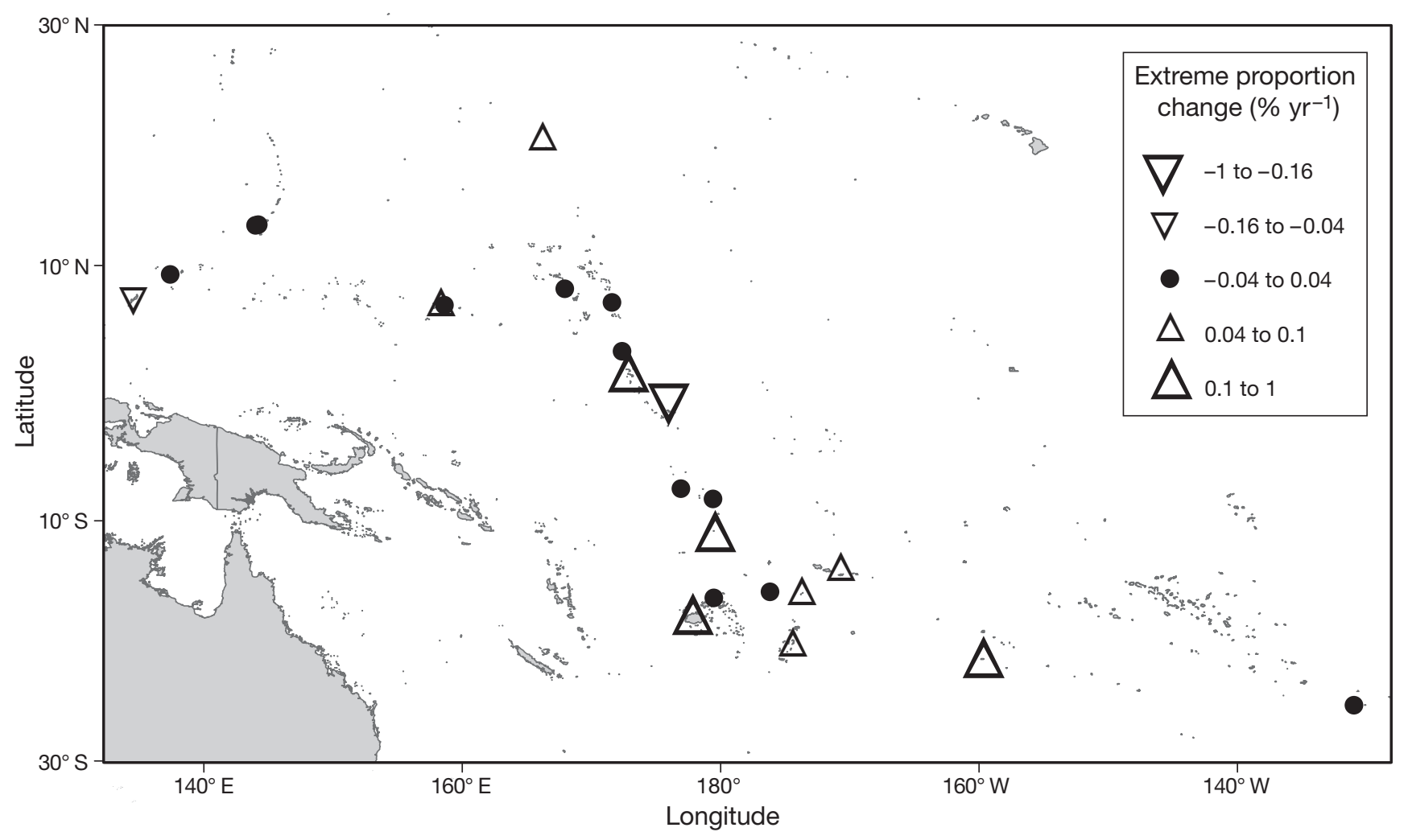

Fig. 4. Change in precipitation extreme proportion across the study region, 1971-2000

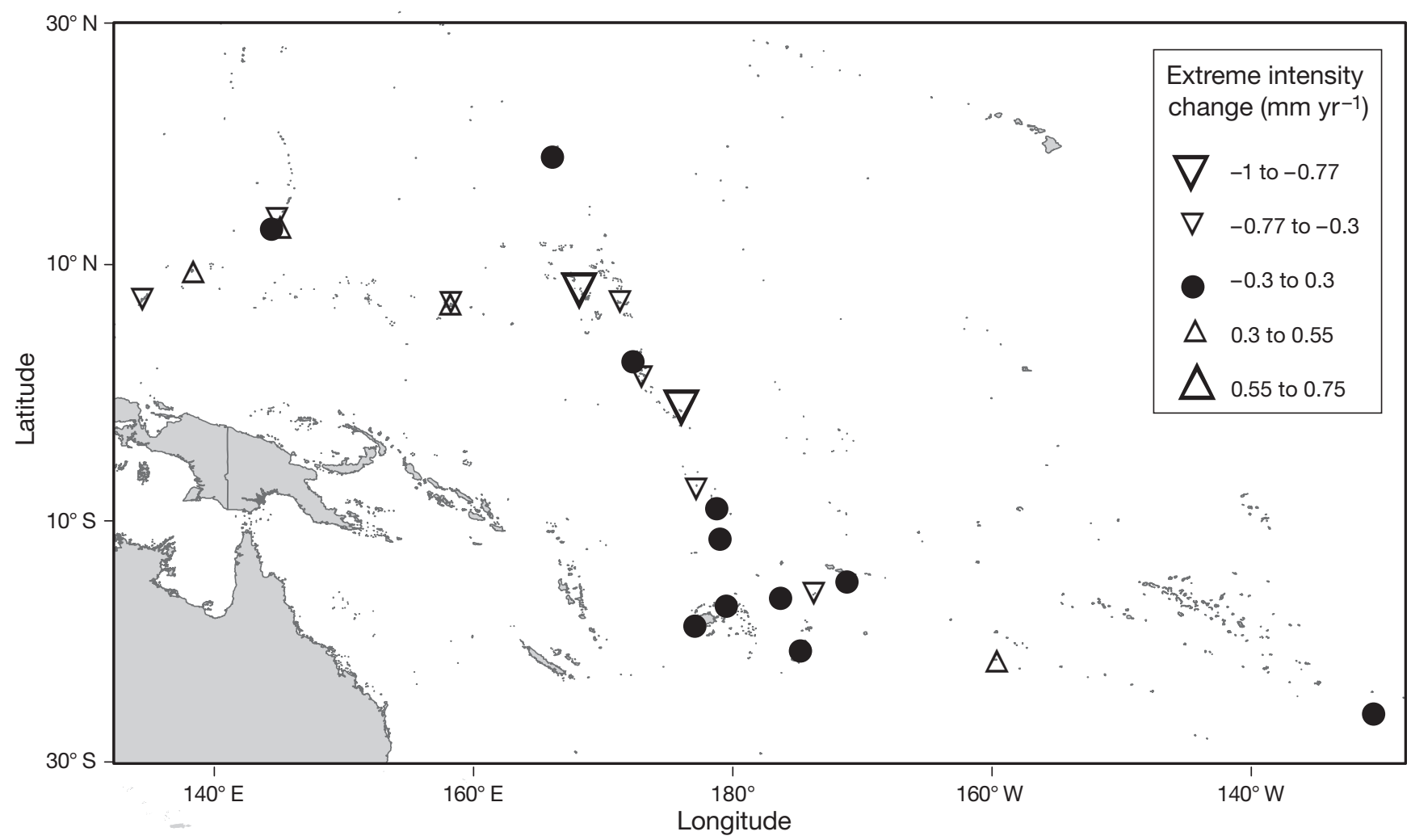

Fig. 5. Change in precipitation extreme intensity across the study region, 1971-2000 


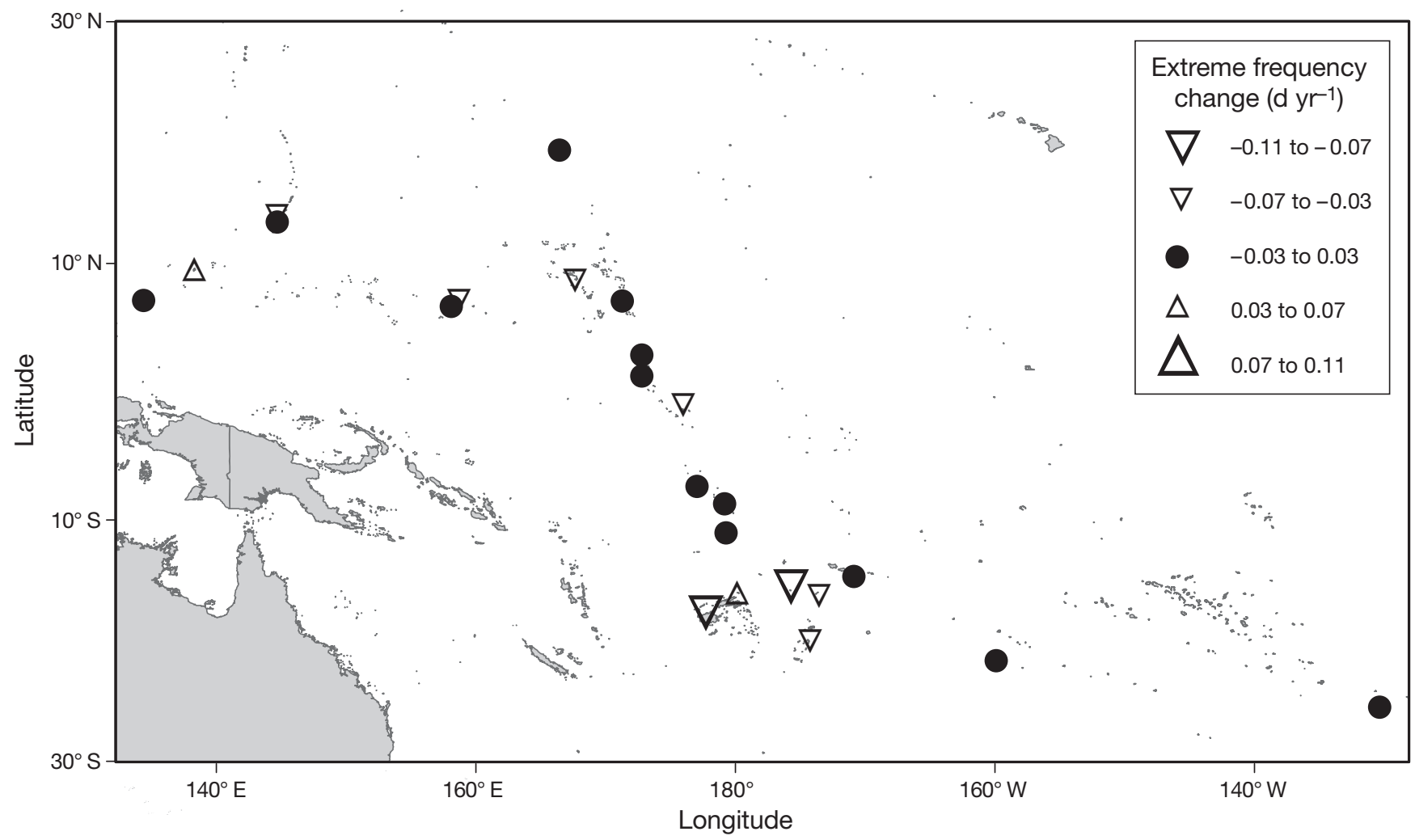

Fig. 6. Change in precipitation extreme frequency across the study region, 1971-2000

precipitation. The implication of this is that there are fewer extreme days, but that they contribute a higher proportion of the total precipitation. The spatial pattern of Fig. 6 also shows that the greatest number of significant changes are located south of the mean SPCZ location. The final indicator analyzed for this part of the study was the number of days with measurable precipitation (Fig. 7). This indicator shows a general decrease in the number of days raining. Many stations show a similar pattern to the patterns in annual precipitation, with the predominant feature being the number of stations showing a negative trend. Fig. 7, combined with the others analyzing extreme proportion and intensity, illustrates that although precipitation may be decreasing, extreme events may be increasing in several locations.

It appears that a distinct spatial pattern exists, with the stations in the southeast representing one cluster, the stations in the northwest representing another, and the stations located between the 2 main spatial clusters (e.g. Tarawa) alternating between the 2 modes. To test this theory, a cluster analysis was performed on the stations using the variables analyzed above. To remove potential collinearity in the data, a factor analysis was performed on the data to reduce the data set to independent factors. Three components, those with eigenvalues greater than 1 and explaining approximately
$88 \%$ of the overall variability, were retained. Next, the factor scores for each station were clustered using an average-linkage approach. This factor analysis-cluster analysis combination is similar to the approach used by Salinger et al. (1995), who clustered stations in the Pacific for a study of an earlier time period. Three clusters were chosen as the optimal solution, based upon an analysis of cluster means and iteration history. The spatial distribution of results is shown in Fig. 8. The factor and cluster analysis shows that there is indeed a pronounced north-south and east-west pattern in the changes in the extreme event indices. The northwest cluster is identified as Cluster 1 and the southeast cluster as Cluster 2 in Fig. 8. There is also a third cluster (Cluster 3): these stations showed little change in proportion and frequency, and low trend significance in annual precipitation. The spatial pattern in the factor loading scores fit the pattern suggested during the 1971 to 1990 study by Morrissey \& Graham (1996), and also the spatial sea surface temperature (SST)circulation explanation by Nitta \& Yamada (1989). As mentioned above, this pattern also supports the conclusions of others that there has been a displacement of the convergences zone in the region under study (Griffiths et al. 2003), as can be seen by the clear clustering south and east of the typical SPCZ location, and another cluster north and west of this location. 


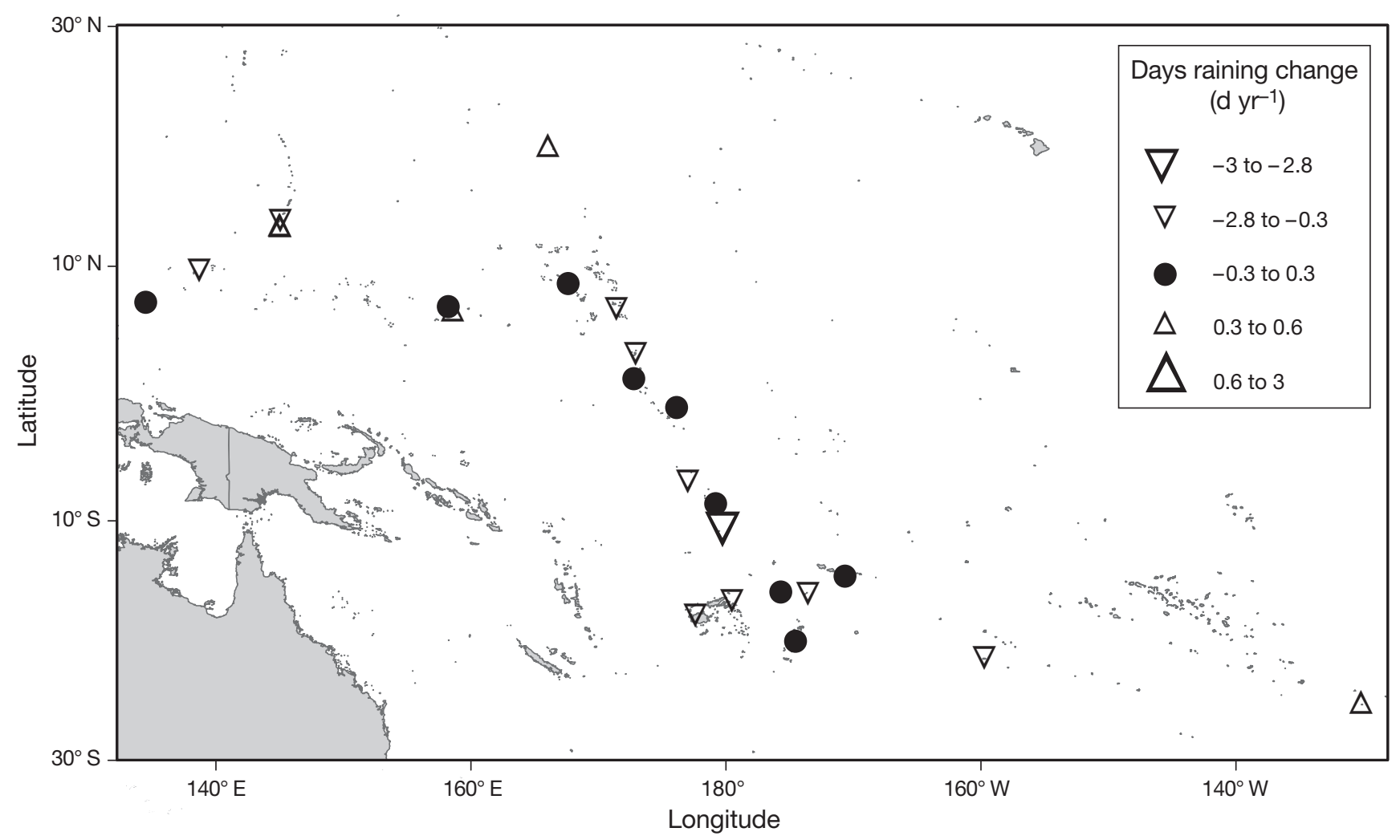

Fig. 7. Change in no. of days with measurable precipitation across the study region, 1971-2000

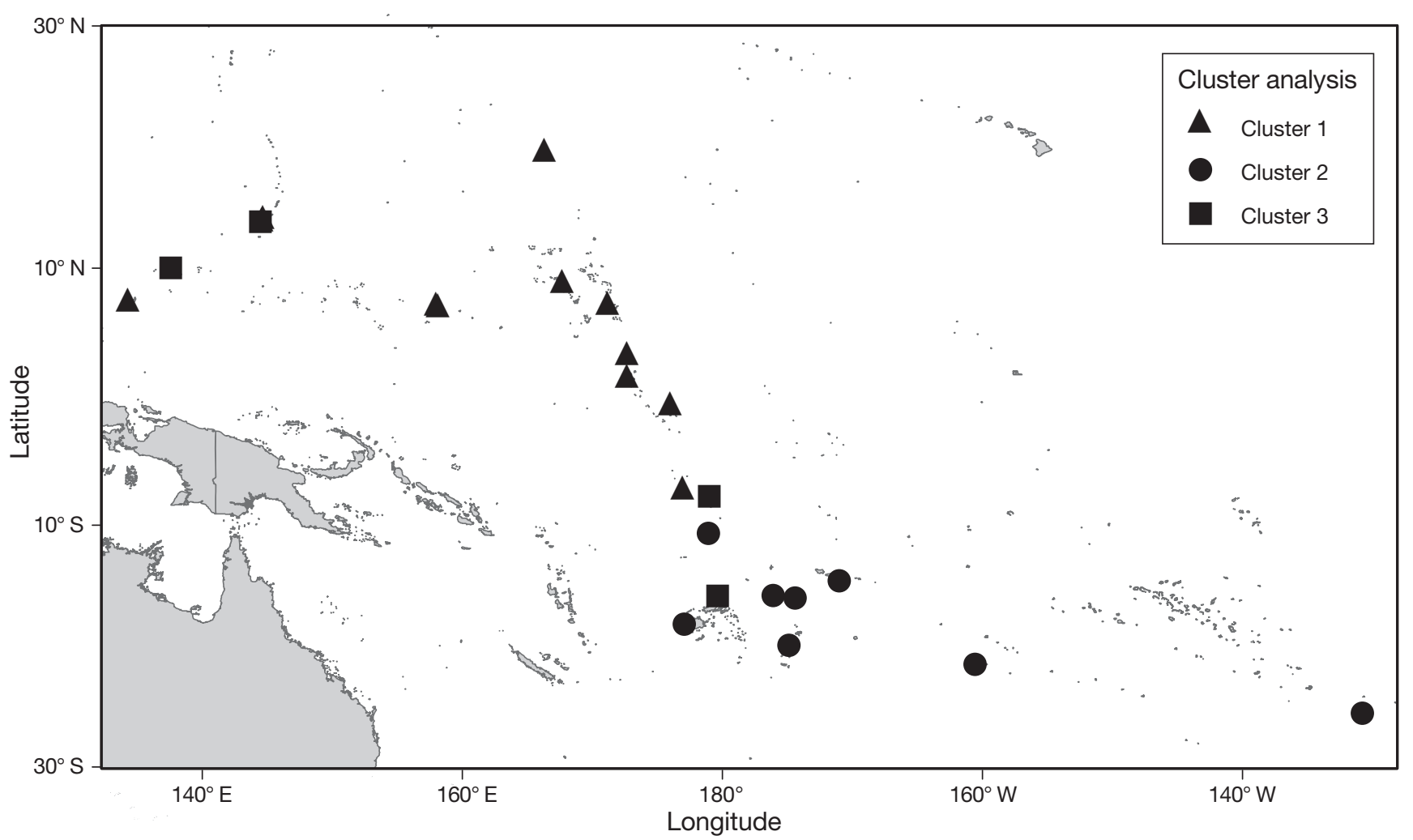

Fig. 8. Location of clusters from cluster analysis of spatial patterns 


\subsection{Longer-term changes in monthly precipitation}

The final part of this study expanded the analysis using monthly data to investigate longer-term changes in precipitation in the tropical Pacific. Using the monthly precipitation data set from the PACRAIN, and the strict data quality control measures described above (e.g. 99\% data completeness, no significant metadata problems etc.), a set of 14 stations was selected. The time period, 1951 to 2004, represented the longest time frame for which reliable precipitation data could be obtained for enough stations to allow spatial patterns in the changes to develop.

As Folland et al. (2002) pointed out, the IPO is thought of as a Pacific-wide manifestation of the Pacific Decadal Oscillation (Biondi et al. 2001, Mantua \& Hare 2002). It is defined as a function of a combination of the empirical orthological functions (EOF) analysis using 2 different variables: the third EOF of global sea surface temperatures and the third EOF of global nighttime maritime air temperature. Salinger et al. (2001) noted that there have been 3 distinct phases of the IPO during the 20th century: positive phases in 1922 to 1944 and 1978 to 1998, and a negative phase between 1946 and 1977. The pattern of these phases was summarized by Folland et al. (2002), who noted that when the IPO is in its positive phase, the SPCZ is displaced northeast, whereas a southwest displacement occurs during the negative phase of the IPO. During the positive phase of the IPO, SST anomalies over the North Pacific are negative, while equatorial SST anomalies in the tropical Pacific are positive (Salinger et al. 2001). Griffiths et al. (2003) also noted that the decadal changes brought on by the IPO originate in the changes in the atmospheric mass between the eastern and western parts of the study region. The IPO creates pressure changes in the South Pacific that influence the amount of convection and precipitation, resulting in a change in position of the SPCZ.

Using the definitions of Salinger et al. (2001), maps of the changes in the monthly precipitation were made for 3 separate time periods: the entire period of record (1951-2004; Fig. 9), the time period of the positive phase of the IPO (1978 to 1998; Fig. 10), and time period of the negative phase for which sufficient data were available (1951 to 1977 ; Fig. 11). For the overall time period, the data show that the changes are almost split between positive and negative. The patterns

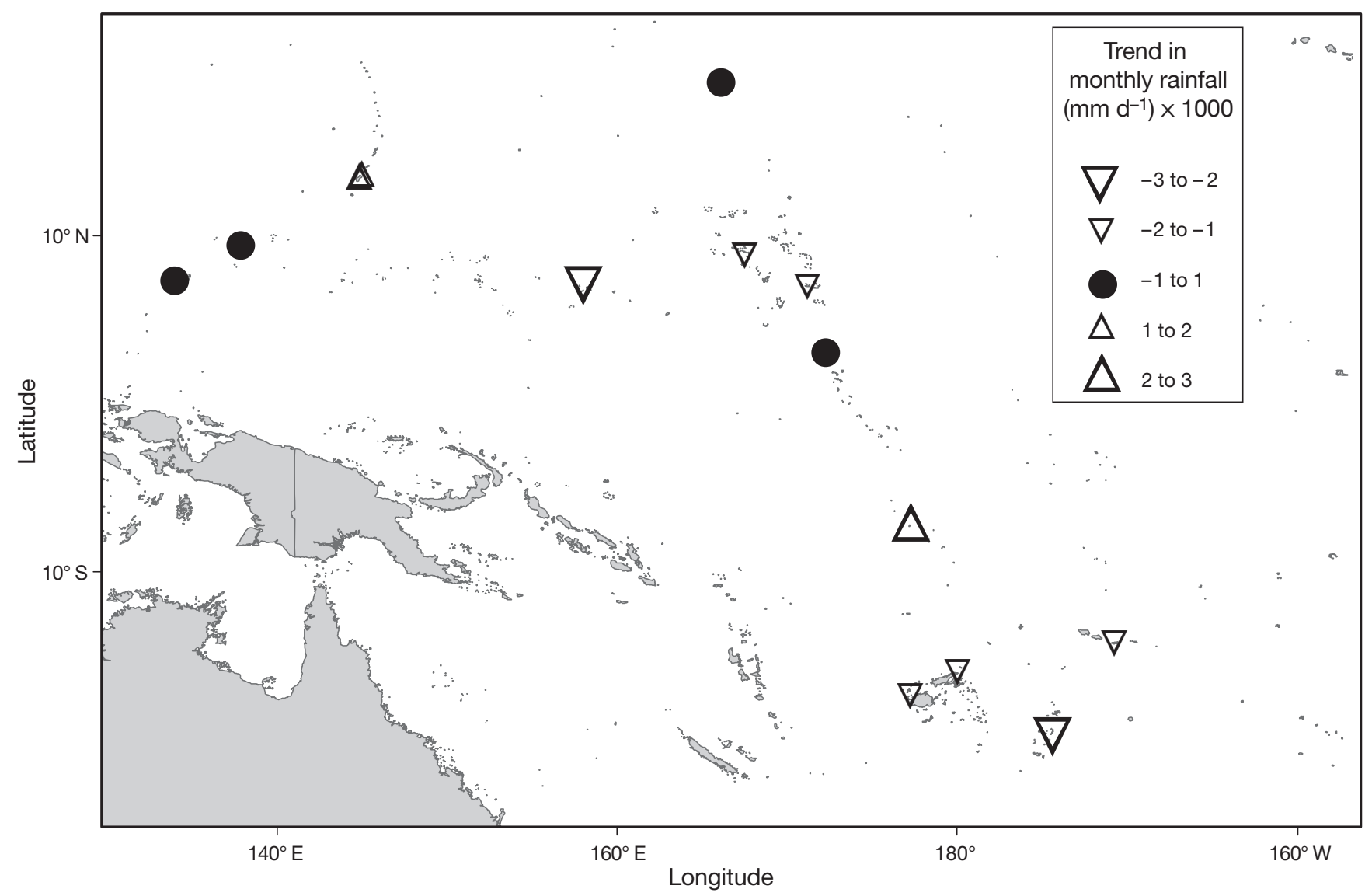

Fig. 9. Change in total monthly precipitation, 1951-2004 


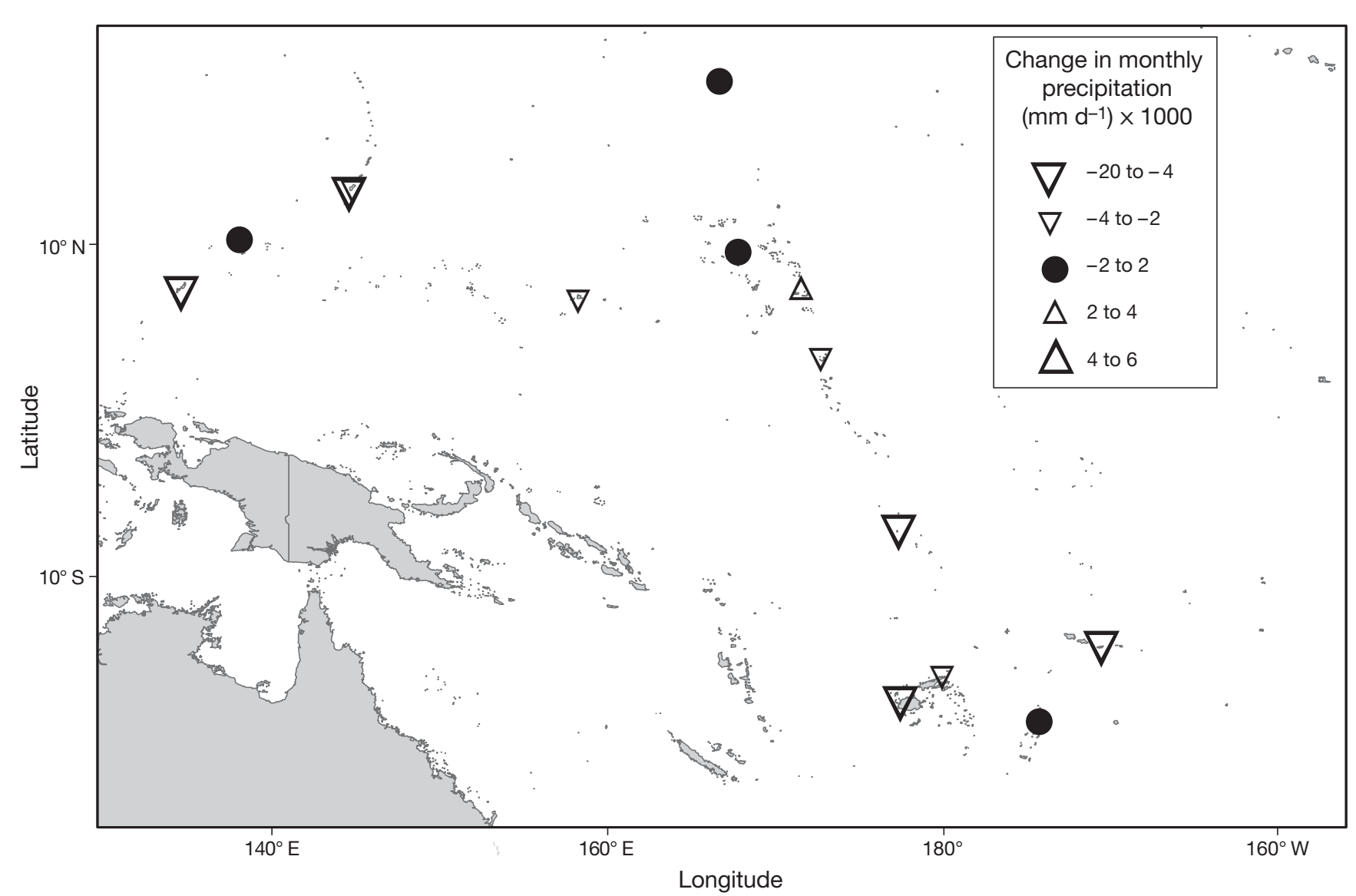

Fig. 10. Change in monthly precipitation during positive phase of the IPO, 1978-1998

identified above are evident over the long time period as well. The southern stations (e.g. Pago Pago, Nadi, Ha'apai) showed significant decreases, as did a group in the central equatorial region (e.g. Ponape, Majuro, Kwajelein). The northwestern stations all experienced a slight increase in precipitation. This pattern is similar to the pattern described above in the analysis of the daily data, and indicates an even more pronounced shift in the regional atmospheric circulation associated with changes in the location of the ITCZ and SPCZ in the area.

Division of the years into positive and negative phases of the IPO illustrates the relative changes in the monthly precipitation patterns during different climatic regimes across the western Pacific.

The change data for the positive phase reveal that $75 \%$ of the stations analyzed showed a decrease in precipitation from 1978 to 1998. For example, the change value for Nui of -0.012 represents a decrease of over $100 \mathrm{~mm}$ over the time period. The pattern of Fig. 11 is much less spatially coherent, further suggesting that the positive phase is more significant in explaining the overall patterns in the data changes. For example, the overall mean absolute change of the negative phase is less than half of that of the positive phase. The positive phase pattern most closely resembles the overall spatial pattern shown in Figs. $2 \& 9$.

\section{SUMMARY AND CONCLUSIONS}

This study presents the results of an analysis of historical changes in tropical Pacific rainfall using the PACRAIN, a raingauge database for the Pacific that contains almost 800 sites, some with records dating back to the late 1800s. Although previous studies examined daily data over shorter time periods (e.g. Morrissey \& Graham 1996), or analyzed a different geographical data set over a similar time frame (e.g. Griffiths et al. 2003), this is the first study to examine changes for the climate normal period (1971 to 2000) using a larger geographical set of stations. Although there are almost 800 stations in the data set, a highly selective quality control left 24 stations with high data completeness and quality that were ultimately analyzed in this study. The annual change pattern of a decrease in precipitation in the southern tropical Pacific islands, and little trend or a slight increase in 


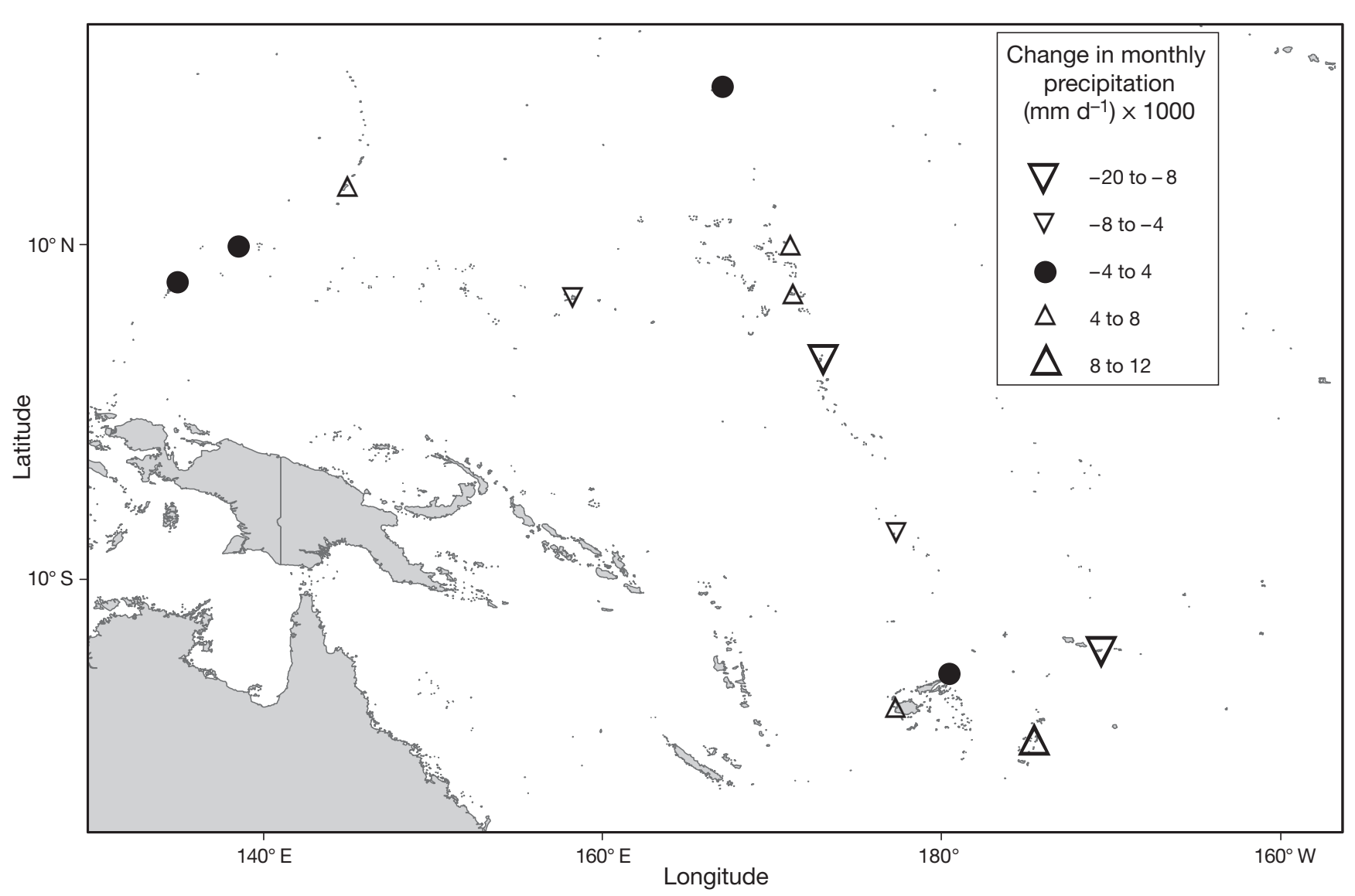

Fig. 11. Change in monthly precipitation during negative phase of the IPO, 1951-1977

the northern equatorial locations, is similar to results of previous studies. A cluster analysis of all the change variables indicates a clear north-south delineation in the characteristics exhibited by the different locations.

The decrease in overall precipitation noted over the southern portion of the study region is likely associated with a displacement of the SPCZ during the study period. The pattern of these phases was summarized by Folland et al. (2002), who noted that when the IPO is in its positive phase, the SPCZ is displaced northeast, whereas a southwest displacement occurs during the negative phase of the IPO. A longer period of analysis of monthly data also revealed similar spatial and temporal patterns in the data. Results illustrate the potential role of the IPO in explaining a significant amount of the observed changes. There are a greater number of significant changes in the positive phase time period than in the negative phase. The decrease suggests support for the SPCZ displacement mentioned above. Given the large multi-decadal patterns observed in tropical Pacific convective patterns, this finding could have significant implications for future changes in overall precipitation in the region.
In addition to the annual change, patterns in extreme events were also analyzed. Results showed that there were pronounced changes in many of the extreme event indicators analyzed, and that significant regional patterns also exist. The key finding of this study is that the proportional contribution of extreme rainfall to the annual total has increased, particularly in the locations south and east of the mean SPCZ location. This is true even though the other indicators analyzed indicated either a general downward change or no significant change over the period of record. For the locations in the southeastern portion of the study region, the number of extreme days decreased, the impact of extreme rainfall intensity declined, and the number of days with rain decreased. Thus, although the overall amount of rain is decreasing, the total extreme rainfall is decreasing less rapidly (and therefore becoming more significant) than the non-extreme rainfall. The examples of Udu Point, Fiji, illustrate this point, whereby a significantly greater amount of overall rainfall is explained by extreme events. However, it should be pointed out that given the complexities of the causes of precipitation shifts in the region (e.g. changes in ENSO pat- 
terns, tropical cyclone location and intensity, and the relationship between sea temperature anomalies), there are likely complexities in the mechanistic processes other than a displacement of the SPCZ. The data show changes in the characteristics and nature of extreme event proportion and severity, and these results could have significant implications for local natural and human resources.

Acknowledgements. We thank the NOAA Office of Global Programs for funding this research, and the directors of the meteorological services in the Pacific for their help and support in providing data. In addition, we thank Ms. Stephanie Buway for her cartographic assistance.

\section{LITERATURE CITED}

Biondi F, Gershunov A, Cayan DR (2001) North Pacific decadal climate variability since 1661. J Clim 14:5-10

Easterling DR, Horton B, Jones PD, Peterson TC and 7 others (1997) Maximum and minimum temperature trends for the globe. Science 277:364-367

Folland CK, Renwick JA, Salinger MJ, Mullan AB (2002) Relative influences of the Interdecadal Pacific Oscillation and ENSO on the South Pacific Convergence Zone. Geophys Res Lett 29:1643, doi: 10.1029/2001GLO14201

Greene JS, Morrissey ML (2000) Validation and uncertainty analysis of satellite rainfall algorithms. Prof Geogr 52: 247-258

Griffiths GM, Salinger MJ, Leleu L (2003) Trends in extreme daily rainfall across the South Pacific and relationship to the South Pacific Convergence Zone. Int J Climatol 23: 847-869

Groismen P (2000) Changes in the probabilities of heavy precipitation: important indicators of climate change. Clim Change 42:297-311

Houghton JT, Ding Y, Griggs DJ, Noguer N, van der Linden PJ, Dai X, Maskell K, Johnson CA (2001) Climate change 2001: the scientific basis. Contributions of Working Group II to the Third Assessment Report of the Intergovernmental Panel on Climate Change (IPCC). Cambridge University Press, Cambridge

Editorial responsibility: Gregory Jones, Ashland, Oregon, USA
Mantua NJ, Hare SR (2002) The Pacific decadal oscillation. J Oceanogr 58:35-44

Manton MJ, Della-Marta MR, Haylock KJ, Hennessy KJ and 22 others (2001) Trends in extreme daily rainfall and temperature in Southeast Asia and the South Pacific. Int J Climatol 21:269-284

Meehl GA, Karl T, Easterling DR, Changnon S and 13 others (2000) An introduction to trends in extreme weather and climate events: observations, socioeconomic impacts, terrestrial ecological impacts, and model projections. Bull Am Meteorol Soc 81:413-416

Morrissey ML, Graham NE (1996) Recent trends in rain gauge precipitation measurements from the tropical Pacific: evidence for an enhanced hydrologic cycle. Bull Am Meteorol Soc 77:1207-1219

Morrissey ML, Shafer MA, Postawko SE, Gibson B (1995) The Pacific rain gage rainfall database. Water Resour Res 31: 2111-2113

Nicholls N (1995) Long-term climate monitoring and extreme events. Clim Change 31:231-245

Nicholls N, Murray B (1999) Workshop on indices and indicators for climate extremes: Asheville, NC, USA, 3-6 June 1997. Breakout Group B: precipitation. Clim Change 42: 23-29

Nitta T, Yamada S (1989) Recent warming of the tropical sea surface temperature and its relationship to the Northern Hemisphere circulation. J Meteorol Soc Jpn 67:375-383

Peterson TC, Taylor MA, Demeritte R, Duncombe DL and 13 others (2002) Recent changes in climate extremes in the Caribbean region. J Geophys Res 107:(D21):4601, doi: 10.1029/2002JD002251

Postawko SE, Morrissey ML, Gibson B (1994) The Schools of the Pacific Rainfall Climate Experiment: combining research and education. Bull Am Meteorol Soc 75:1260-1266

Salinger MJ, Basher RE, Fitzharris BB, Hay JE, Jones PD, MacVeigh JP, Schmidely-Leleu I (1995) Climate trends in the South-West Pacific. Int J Climatol 15:285-302

Salinger MJ, Renwick JA, Mullan AB (2001) Interdecadal Pacific Oscillation and South Pacific Climate. Int J Climatol 21:1705-1721

Suppiah R, Hennessy KJ (1998) Trends in total rainfall, heavy rain events, and number of dry days in Australia, 19101990. Int J Climatol 10:1141-1164

Vincent DG (1994) The South Pacific Convergence Zone (SPCZ): a review. Mon Weather Rev 122:1949-1969

Submitted: March 15, 2006; Accepted: March 16, 2007

Proofs received from author(s): May 31, 2007 